Supporting information

\title{
Poly(arylene piperidine) anion exchange membranes with tunable $N$-alicyclic quaternary ammonium side chains
}

\author{
Dong Pan, Thanh Huong Pham, Patric Jannasch* \\ Polymer \& Materials Chemistry, Department of Chemistry, Lund University, \\ P.O. BOX 124, SE-221 00, Lund, Sweden \\ *Email: patric jannasch@chem.lu.se
}



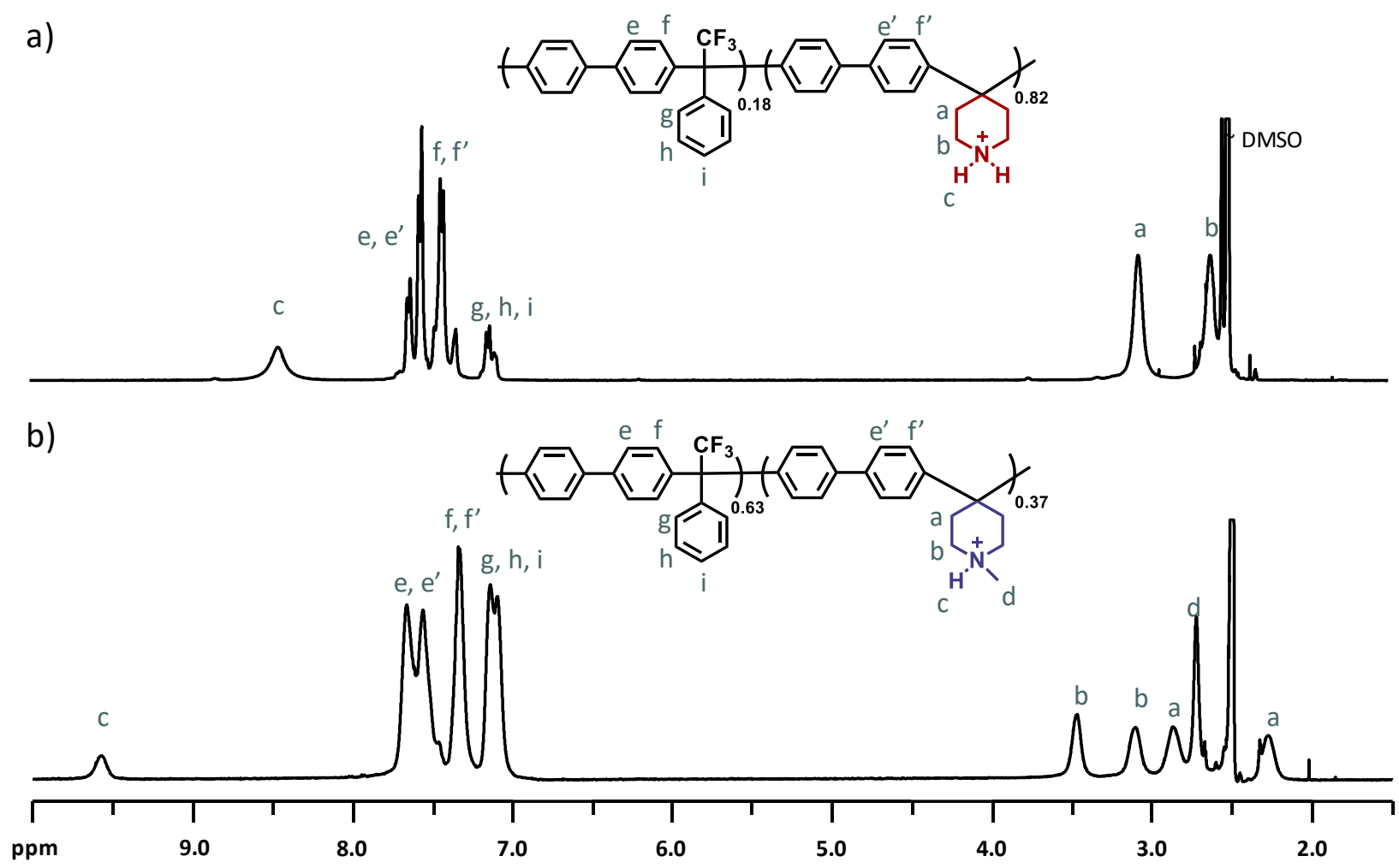

Figure S1. ${ }^{1} \mathrm{H}$ NMR spectra of precursor polymers a) PBPip and b) PBmPip in DMSO-d $d_{6}$ with TFA.

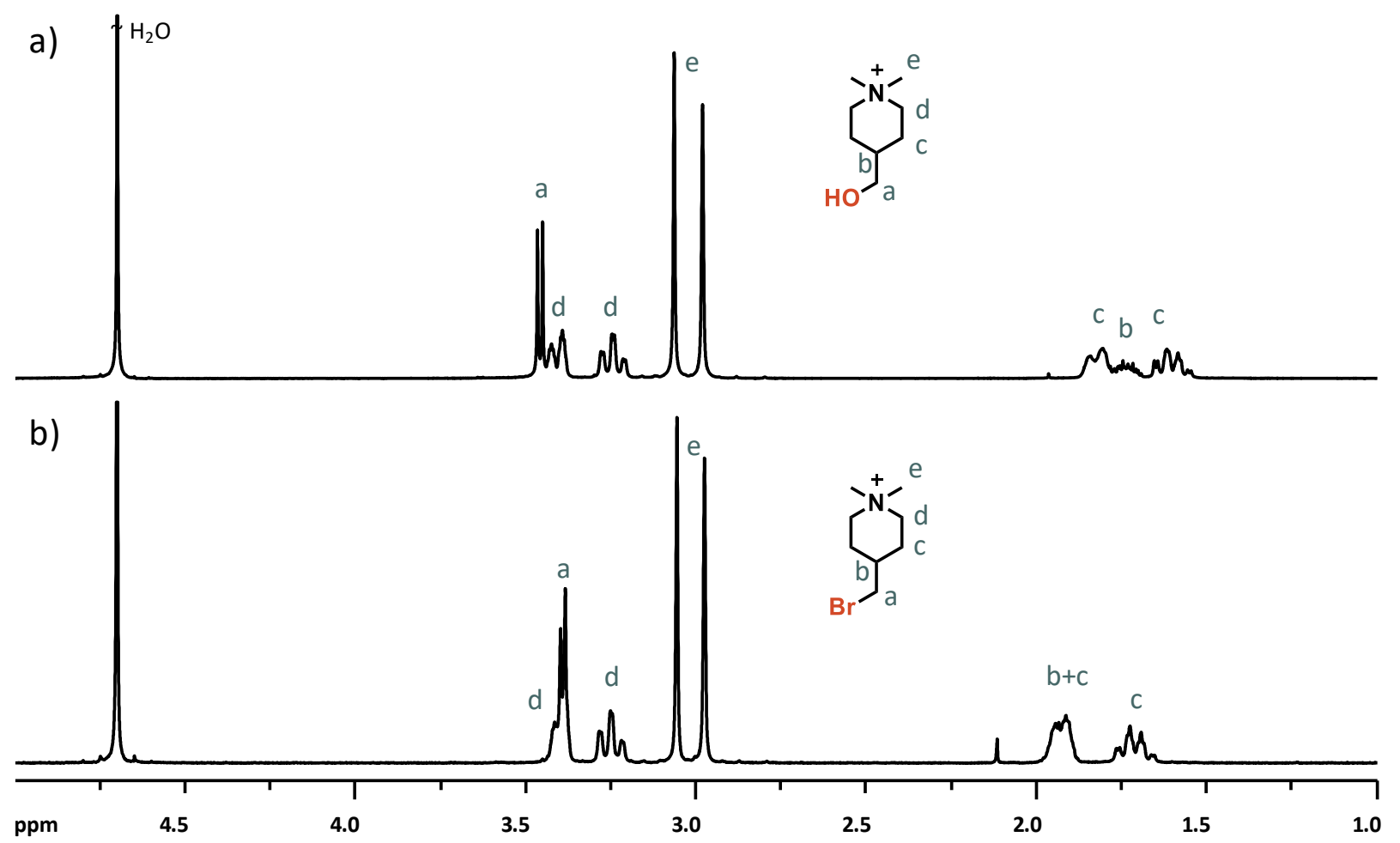

Figure S2. ${ }^{1} \mathrm{H}$ NMR spectra of the intermediate a) $\mathrm{OH}-\mathrm{mDMP}$ and b) $\mathrm{Br}$-mDMP. 


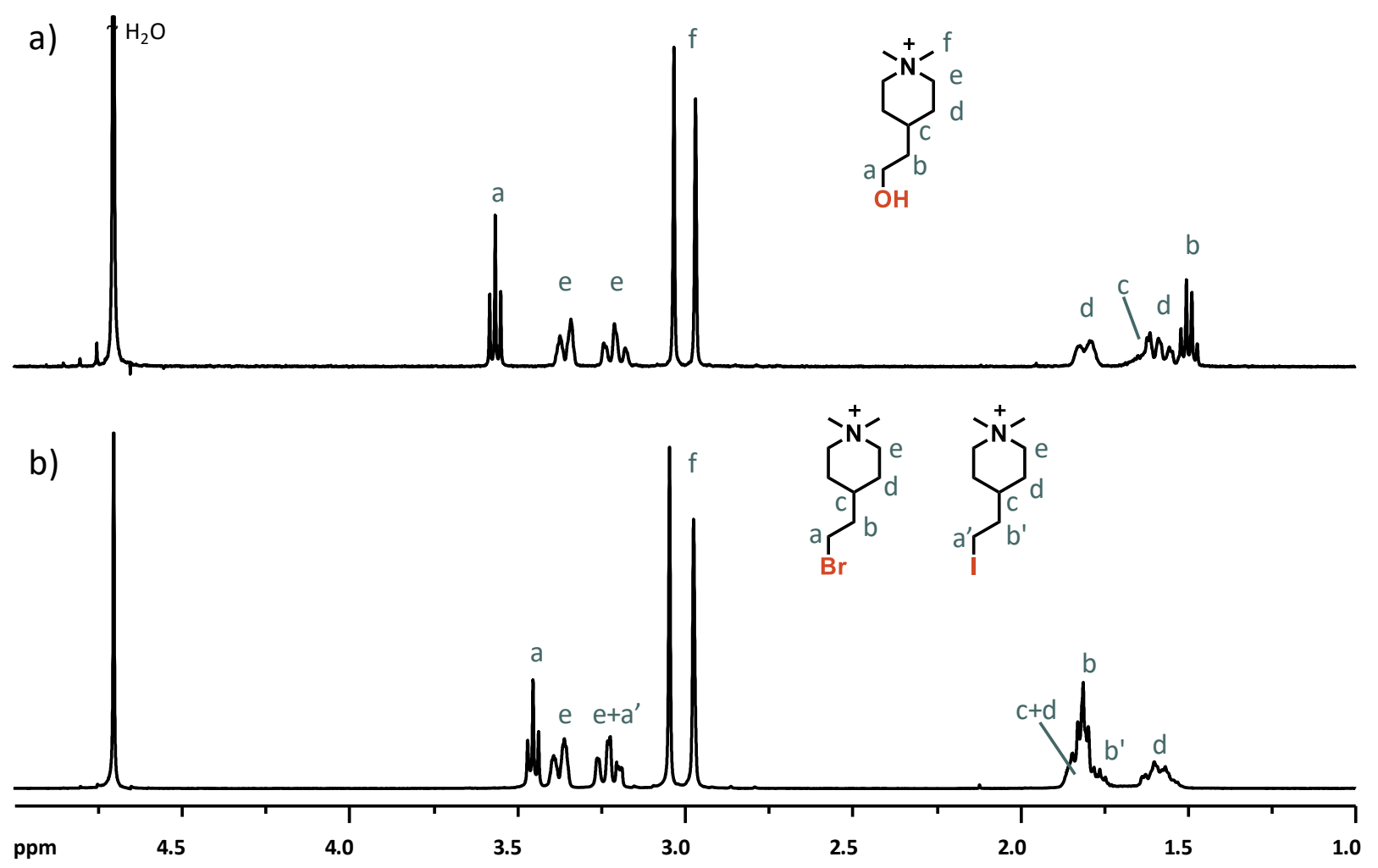

Figure S3. ${ }^{1} \mathrm{H}$ NMR spectra of the intermediate a) $\mathrm{OH}$-eDMP and b) X-eDMP.
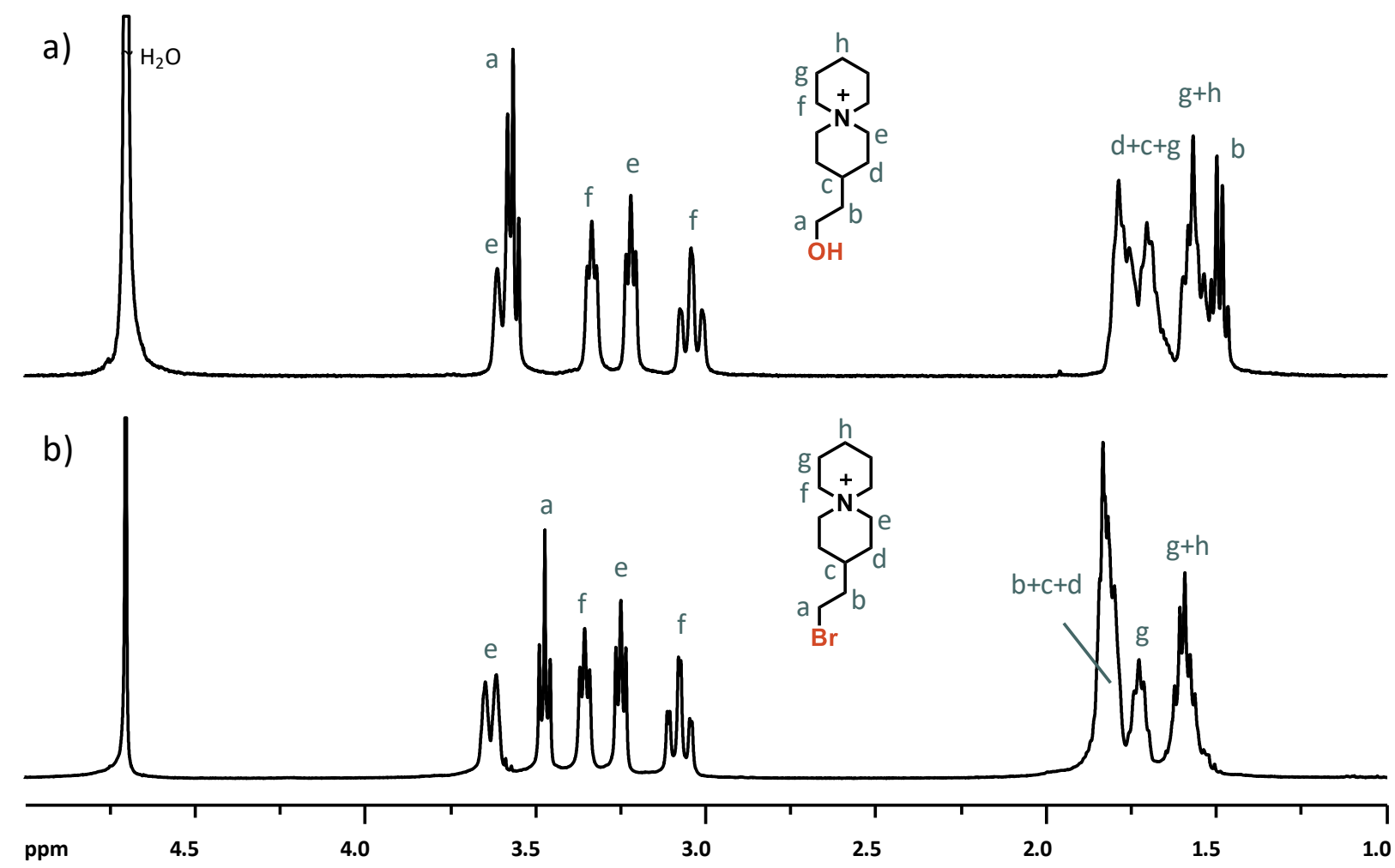

Figure S4. ${ }^{1} \mathrm{H}$ NMR spectra of a) the intermediate $\mathrm{OH}$-eASU and a) $\mathrm{Br}$-eASU. 


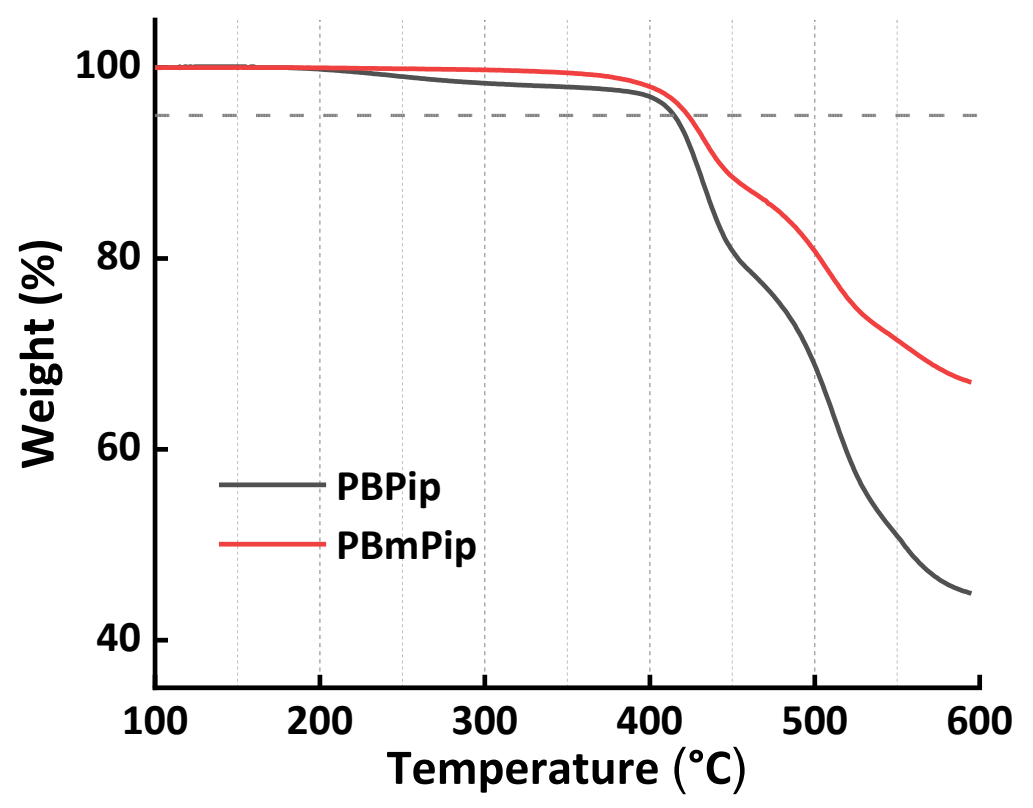

Figure S5. TGA traces of the two precursor polymers measured under $\mathrm{N}_{2}$ flow at a heating rate of $10{ }^{\circ} \mathrm{C}$ $\min ^{-1}$. The dashed line indicates $95 \%$ weight retention limit. 


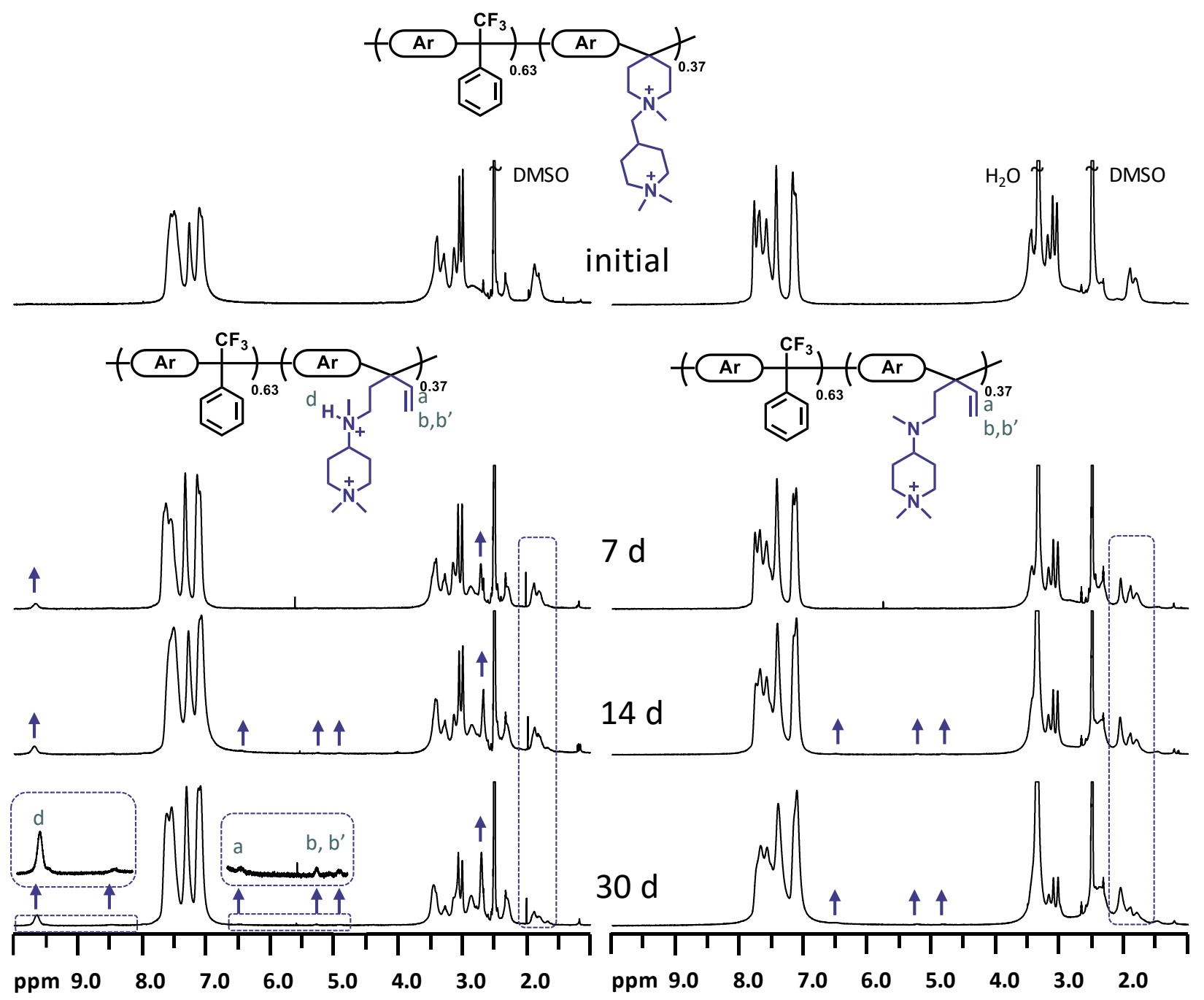

Figure S6. ${ }^{1} \mathrm{H}$ NMR spectra of PBmPip-mDMP AEM before and after alkaline storage in $1 \mathrm{M}$ aq. $\mathrm{NaOH}$ at $80^{\circ} \mathrm{C}$ during 7-30 days. The spectra were recorded using DMSO- $d_{6}$ as solvent and with (left) or without (right) TFA. 


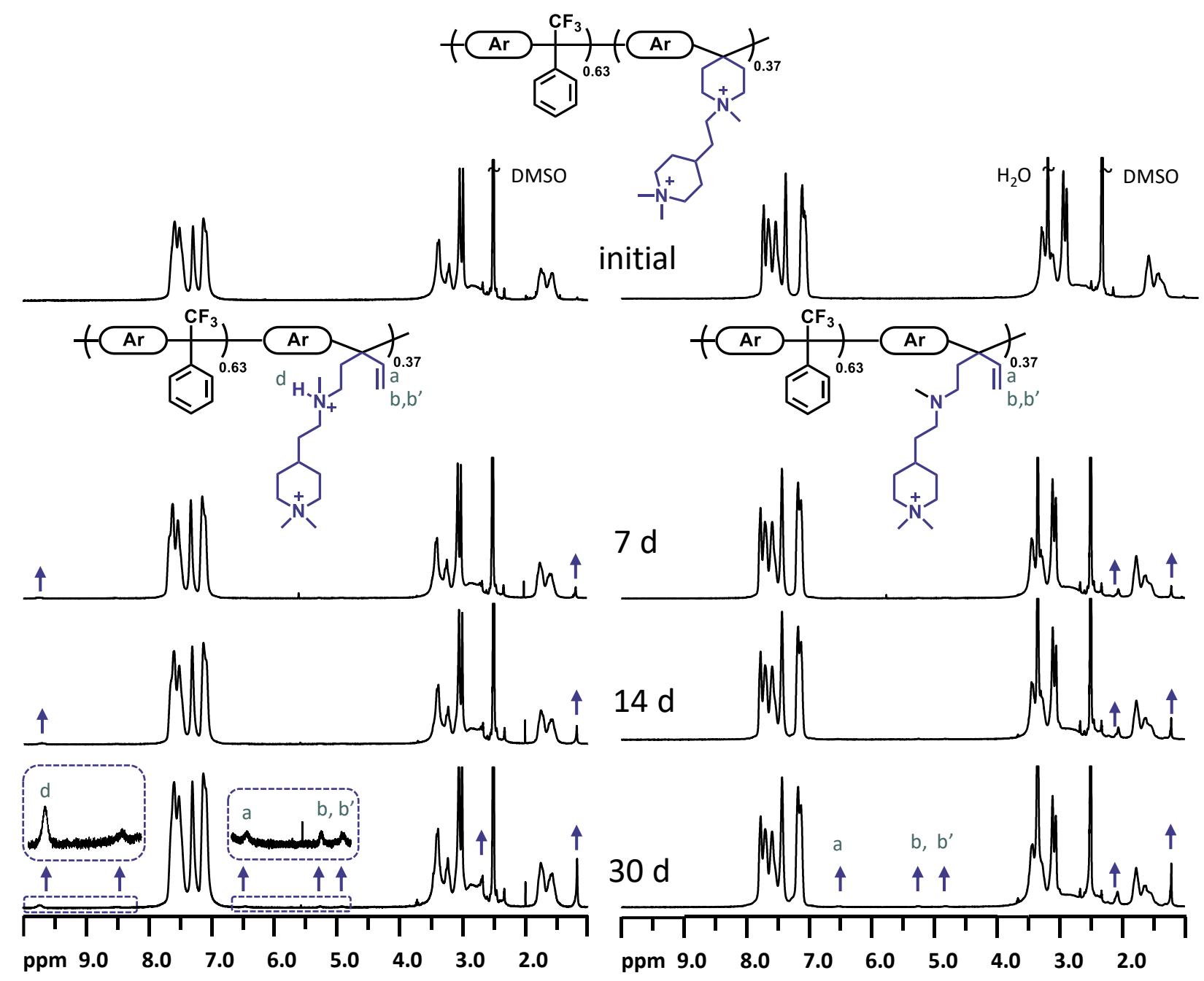

Figure S7. ${ }^{1} \mathrm{H}$ NMR spectra of PBmPip-eDMP AEM before and after alkaline storage in $1 \mathrm{M}$ aq. $\mathrm{NaOH}$ at $80^{\circ} \mathrm{C}$ during 7-30 days. The spectra were recorded using DMSO- $d_{6}$ as solvent and with (left) or without (right) TFA. 


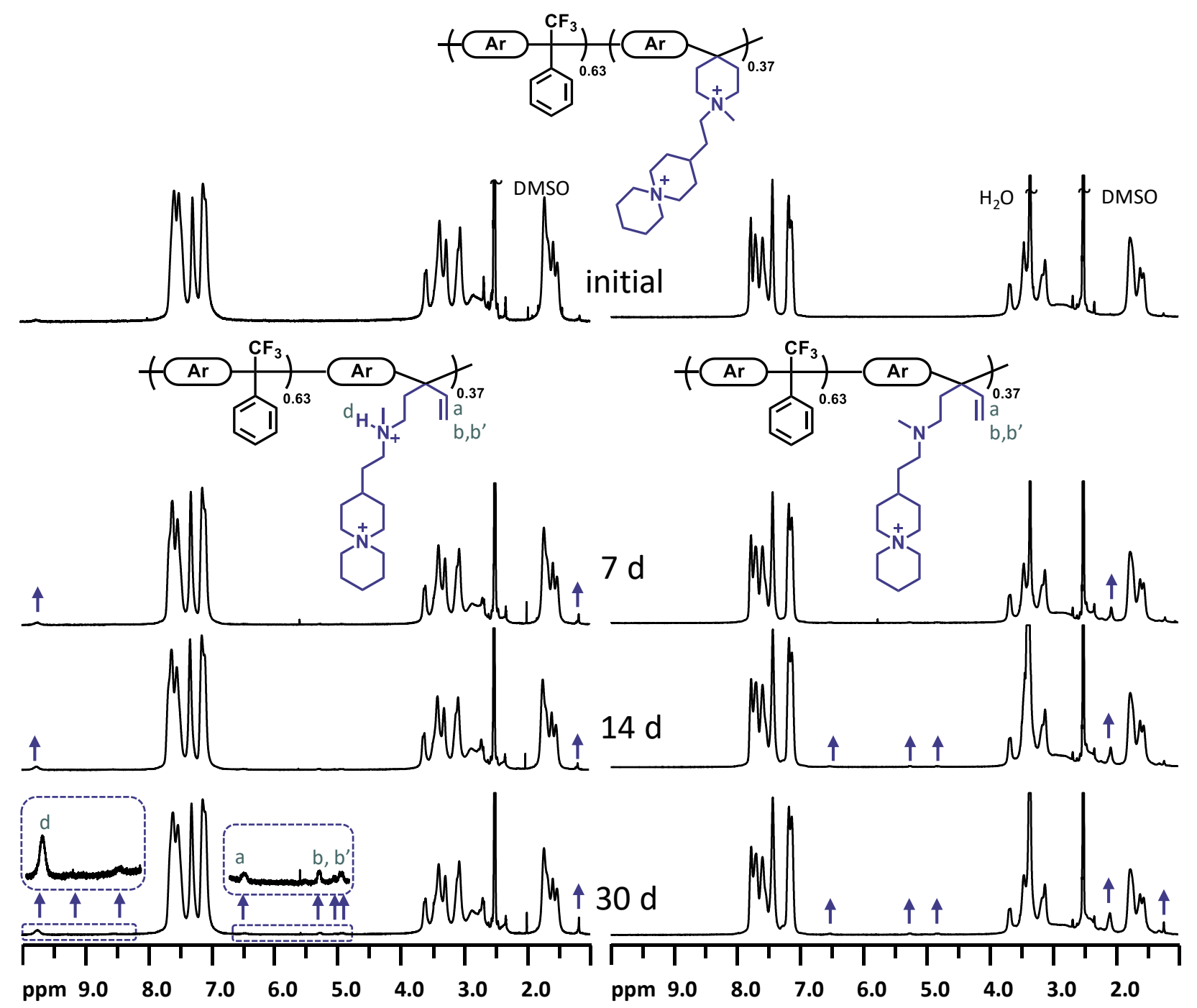

Figure S8. ${ }^{1} \mathrm{H}$ NMR spectra of PBmPip-eASU AEM before and after alkaline storage in $1 \mathrm{M}$ aq. $\mathrm{NaOH}$ at $80^{\circ} \mathrm{C}$ during 7-30 days. The spectra were recorded using DMSO- $d_{6}$ as solvent and with (left) or without (right) TFA. 
a)
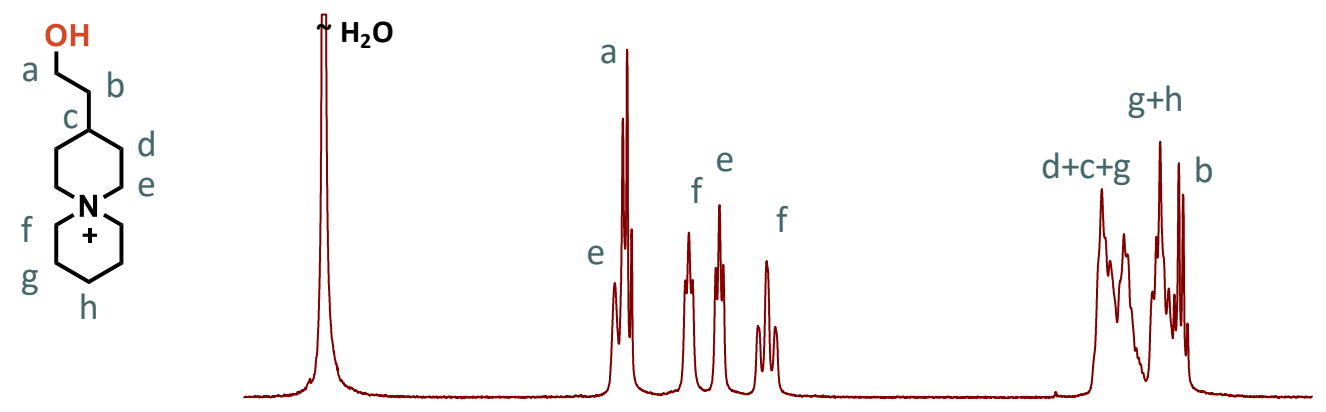

b) $a^{\prime}$
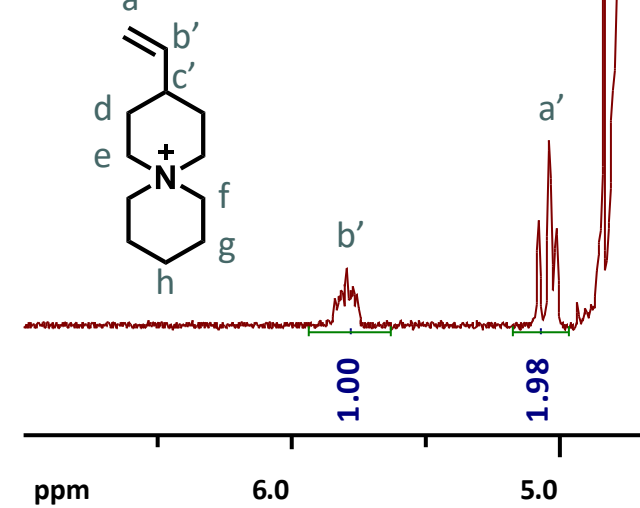

. $\mathrm{H}_{2} \mathrm{O}$

4.0

Figure S9. ${ }^{1} \mathrm{H}$ NMR spectra of a) OH-eASU, which has a chemical structure identical with the degradation product via pathway 4 (Scheme 3 ), b) the $K O D / D_{2} \mathrm{O}$ solution analyzed after the degradation test of PBmPip-eASU. Both spectra were recorded in $\mathrm{D}_{2} \mathrm{O}$. In part $b$, signals $\left(a^{\prime}, b^{\prime}\right)$ shows the presence of the spirocyclic allyl compound formed in pathway 5. A comparison of the integrals of, e.g., signal $b^{\prime}$ and $e$, indicates that another spirocyclic degradation product was present. Analysis by high resolution mass spectroscopy (HRMS) confirmed that OH-eASU and the allylic compound from pathway 4 and 5 , respectively, were the major soluble degradation products, and were present in a 1:11 ratio (Table S1).

Table S1. HRMS results ${ }^{a}$ of the alkaline solution after degradation of PBmPip-eASU.

\begin{tabular}{|l|l|l|l|l|l|l|l|}
\hline Formula & Ion. & $\begin{array}{l}\text { tR / } \\
\text { min }\end{array}$ & $\begin{array}{l}\text { Found } \\
\mathrm{m} / \mathrm{z}\end{array}$ & $\begin{array}{l}\text { Predicted } \\
\mathrm{m} / \mathrm{z}\end{array}$ & mDa* & ppm* & Percentage \\
\hline $\mathrm{C}_{12} \mathrm{H}_{22} \mathrm{~N}$ & $+\mathrm{H}^{+}$ & 4.91 & 180.1753 & 180.1752 & 0.1 & 0.6 & $91.7 \%$ \\
\hline $\mathrm{C}_{12} \mathrm{H}_{24} \mathrm{NO}$ & $+\mathrm{H}^{+}$ & 3.57 & 198.1856 & 198.1858 & -0.2 & -1.0 & $8.2 \%$ \\
\hline
\end{tabular}

a The HRMS experiment was taken on a Micromass QTOF mass spectrometer. Samples are dissolved in 1 $\mathrm{M} \mathrm{KOD} / \mathrm{D}_{2} \mathrm{O}$ and diluted with $2 \%$ formic acid in water. The two caionic compounds generated from the alkaline degradation were confirmed within $2 \mathrm{mDa}$ and $3 \mathrm{ppm}$. Data was obtained by the Hermitianandskew-Hermitiansplitting (HSS) method. 


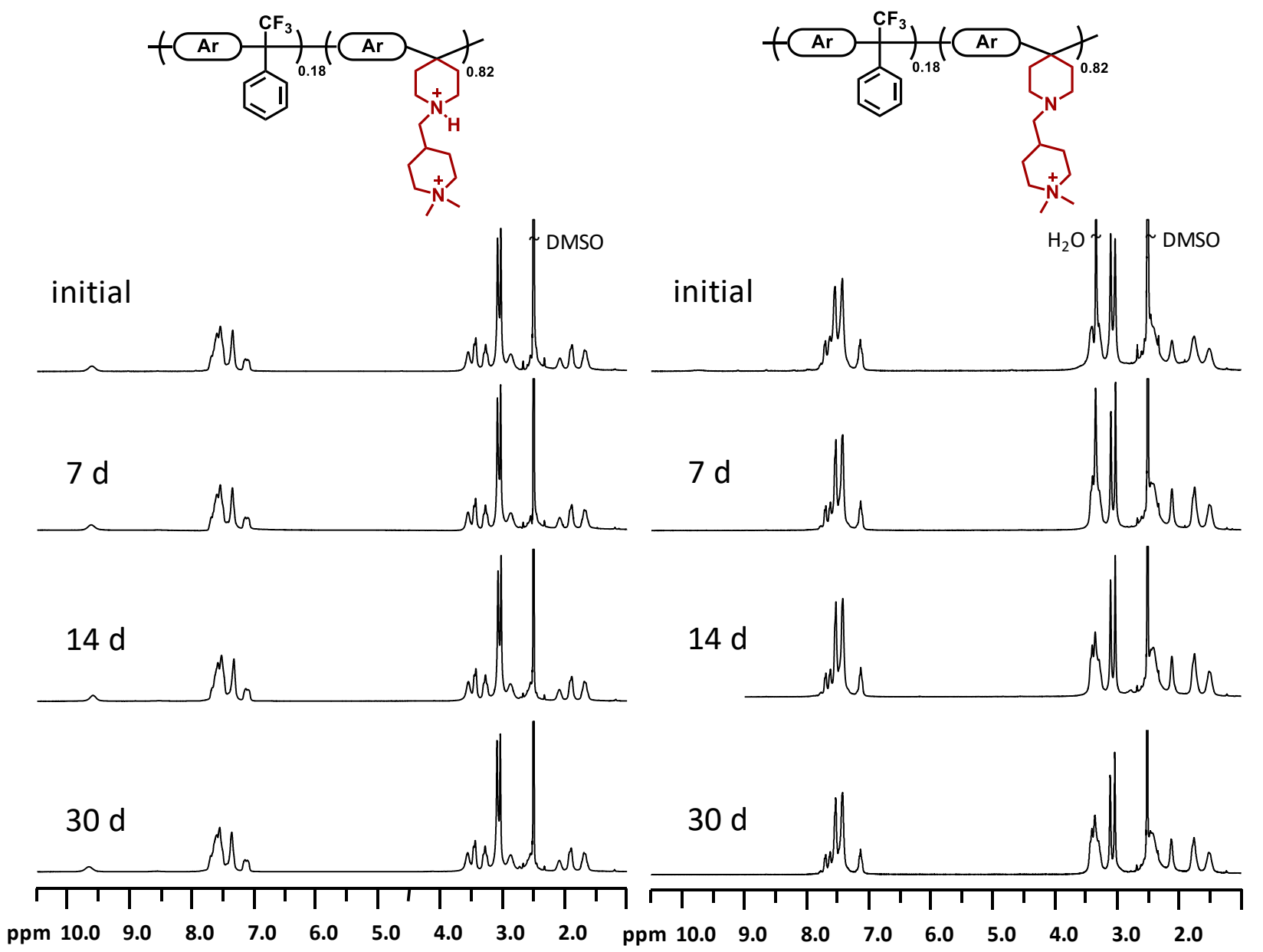

Figure S10. ${ }^{1} \mathrm{H}$ NMR spectra of PBPip-mDMP AEM before and after alkaline storage in $2 \mathrm{M}$ aq. $\mathrm{NaOH}$ at $90{ }^{\circ} \mathrm{C}$ during 7-30 days. The spectra were recorded using DMSO- $d_{6}$ as solvent and with (left) or without (right) TFA. 


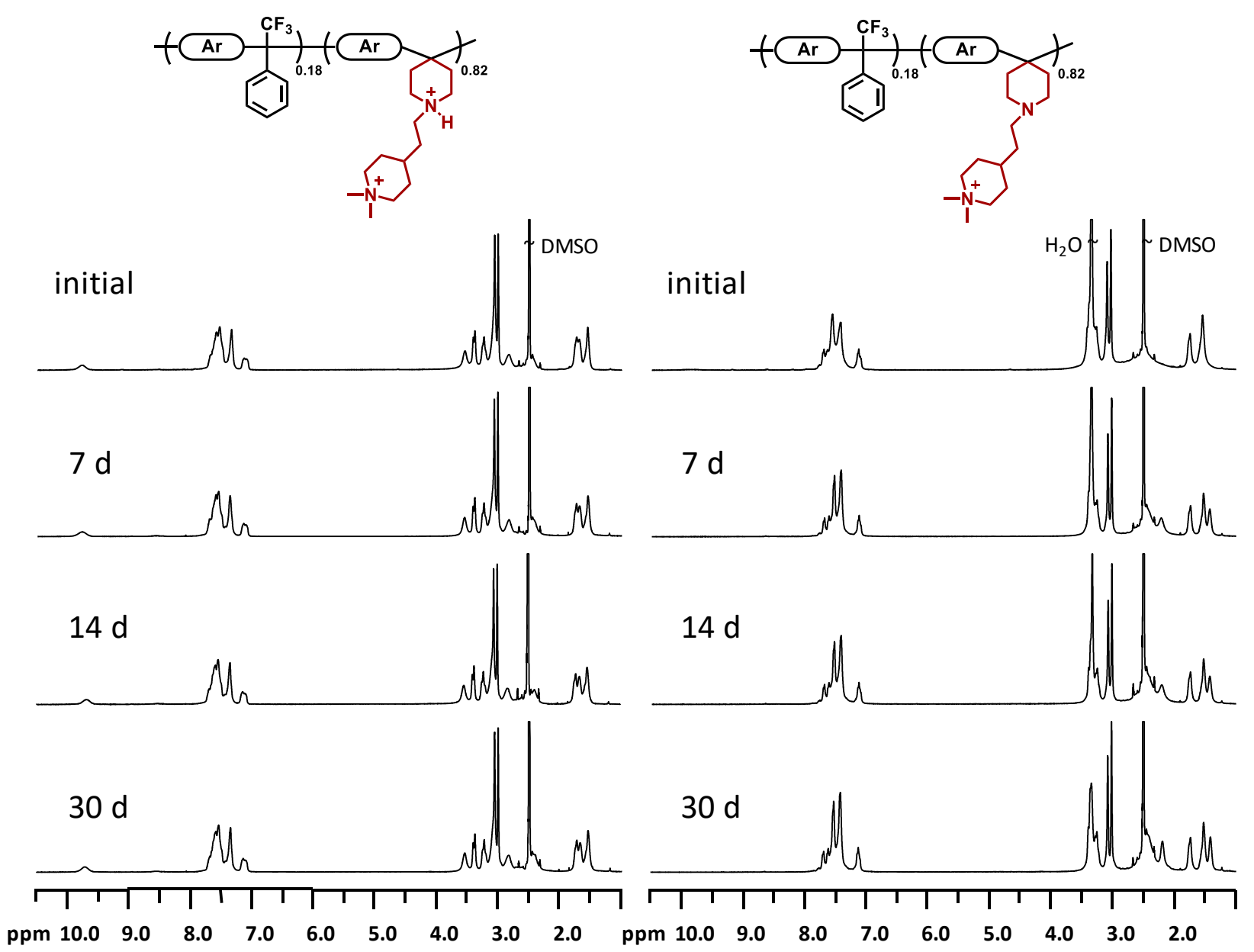

Figure S11. ${ }^{1} \mathrm{H}$ NMR spectra of PBPip-eDMP AEM before and after alkaline storage in $2 \mathrm{M}$ aq. $\mathrm{NaOH}$ at $90{ }^{\circ} \mathrm{C}$ during 7-30 days. The spectra were recorded using DMSO- $d_{6}$ as solvent and with (left) or without (right) TFA. 


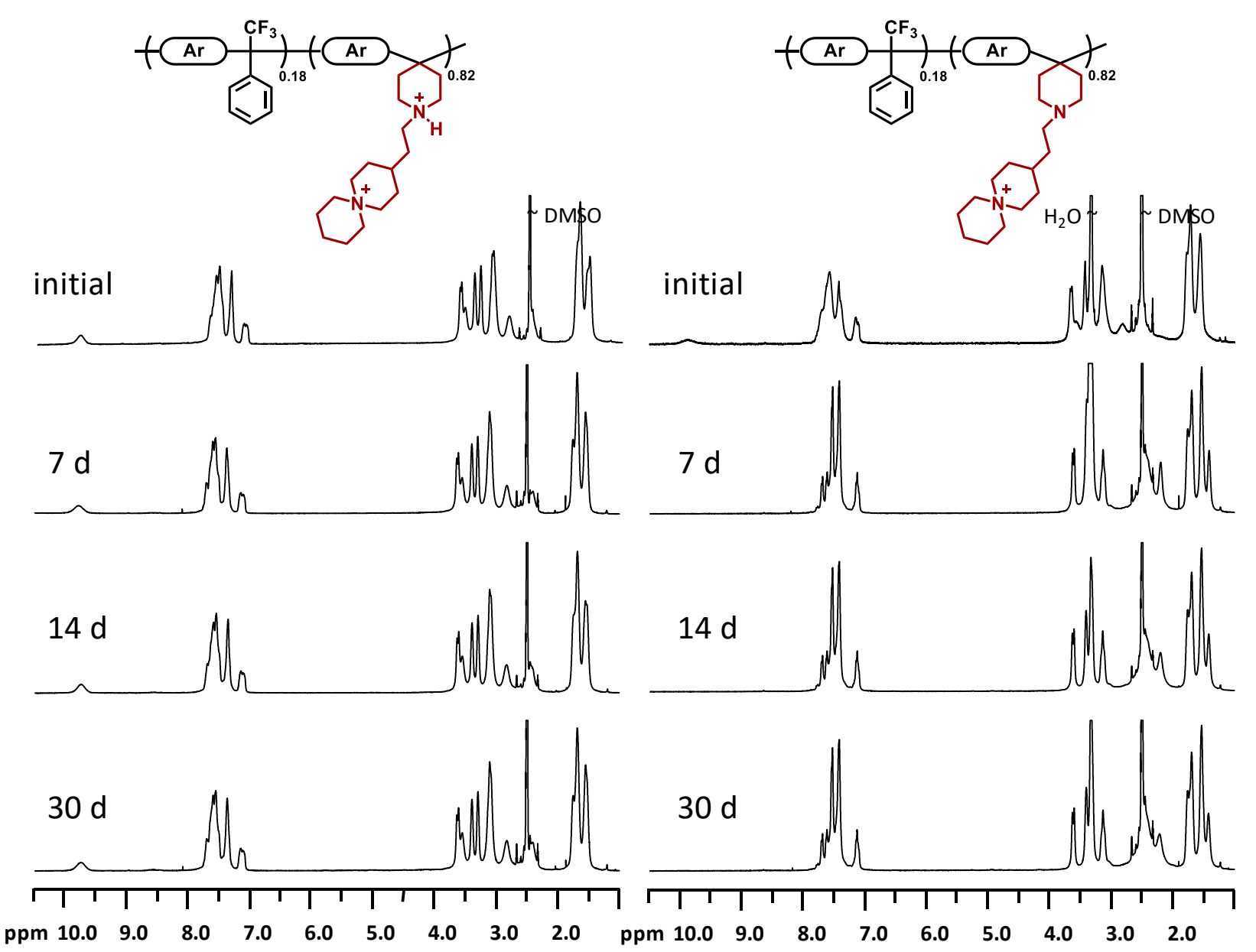

Figure S12. ${ }^{1} \mathrm{H}$ NMR spectra of PBPip-eASU AEM before and after alkaline storage in $2 \mathrm{M}$ aq. $\mathrm{NaOH}$ at $90{ }^{\circ} \mathrm{C}$ during 7-30 days. The spectra were recorded using DMSO- $d_{6}$ as solvent and with (left) or without (right) TFA. 